developers to attempt to have the rights of villages invalidated and for villages to sue. I then extend this model to examine the causes of the historical divergence of peasant property in Britain and France.

It thus seems that the French Revolution was a very important event in the economic history of France. Although the Bourbon monarchs had claimed absolute power, they never achieved the power of nineteenth-century governments. While the physiocrats and other Old Regime reformers had demanded institutional reform, they never achieved an efficient judiciary or better-defined property rights. The French Revolution did have high costs and featured significant amounts of redistribution, but it also involved institutional change. In the long run the Revolution's legacy may well be centralization of power and greatly simplified property rights.

Jean-Laurent Rosenthal, University of California, Los Angeles

\title{
Labor Market Institutions and the Geographic Integration of Labor Markets in the Late Nineteenth-Century United States
}

The late nineteenth century is widely regarded as the era in which a national economy first emerged in the United States. ${ }^{1}$ The elaboration of national rail and telegraph networks in the decades after the Civil War lowered the cost and increased the speed of transportation and communication. While manufacturers in many industries consolidated national markets for their products, a variety of new financial intermediaries promoted increasing arbitrage in the market for capital. My dissertation examines the extent of labor market integration at this time.

There are two complementary ways of approaching the question of labor market integration. First, integration may be explored qualitatively by examining the institutions through which labor market adjustment operated. Second, the correlation of wage movements across markets and the magnitude of geographic wage differentials can be used to provide quantitative indexes of the impact of the operation of these market institutions.

In contrast to the increasing specialization and centralization of intermediation in financial and product markets, labor market adjustment continued to rely primarily on informal, word-of-mouth communication channels provided by family and friends. Although the number of employment agencies and publicly sponsored labor exchanges operating in local markets increased considerably, they played only a minor role in directing long-distance movements of labor. These formal labor market intermediaries attracted a good deal of attention around the turn of the century, and published results of a number of contemporary studies make it possible to construct a clear picture of the extent and characteristics of their activities. It appears that most job-seekers were deterred from using employment agencies by the risks of opportunistic behavior to which they were exposed. As a result, employment agencies were important only in directing the first wave of long-distance migrants. Once an established industrial work force was in place, informal communication channels replaced formal intermediaries.

${ }^{1}$ This dissertation was completed in 1988 at the Economics Department of Stanford University under the supervision of Paul David and Gavin Wright. 
To assess the performance of labor markets after the Civil War in quantitative terms I use annual wage data collected by the U.S. Department of Labor covering 23 occupations and 12 major U.S. cities from 1870 to 1898 . To adjust these data for intercity differences in the cost of living, I construct city-specific retail price indexes at several dates during this period.

Despite considerable occupational variation, year-to-year wage movements were, on average, positively correlated across cities. But this is less a reflection of labor market integration than of increasing integration in other sectors of the economy, for once I take account of the effect of aggregate fluctuations in prices and economic activity there is no perceptible correlation of wage movements.

Measurements of intercity real wage differentials for all occupations and for disaggregated occupational groups confirm the absence of labor market integration. Although real wage rates in San Francisco converged toward eastern levels following completion of the transcontinental railroad, wage differentials between other cities were large and persistent. Most striking is the finding that real wages in midwestern cities exceeded those in eastern cities by 20 to 25 percent, with no tendency toward convergence. This gap is roughly three to five times as large as the differential found between these regions in the twentieth century. It is also considerably more than the direct costs of transportation between these cities, indicating that these differentials are attributable primarily to the costs of securing information about distant employment opportunities.

Nonetheless, a considerable labor supply response is evident in the differentially rapid growth of population in the high-wage midwestern cities. The population of Chicago, for example, the midwestern city in my sample with the highest wages, grew at nearly 6 percent per year from 1870 to 1900 , about twice as fast as the eastern cities in the sample. For real wage differentials to have persisted without convergence in the face of a supply response of this magnitude, there must have been persistent regional imbalances in the relative growth of labor demand.

In view of the importance of intercity differences in the rate of labor demand growth, it appears important to disentangle the contribution of imperfect labor market integration from that of exogenous supply and demand disturbances in causing the comparatively large real wage differentials of the late nineteenth century. I attempt to do this by estimating a fully identified model of local wage determination for the years 1870 to 1900 , using data from the decennial censuses of manufacturing and population to measure exogenous supply and demand shocks. I then simulate the course of interregional real wage differentials from 1910 to 1940 using the actual values of the exogenous variables and the coefficients estimated for 1870 to 1900 . The resulting counterfactual shows how real wage differentials would have evolved, holding the extent of labor market integration constant at its late nineteenth-century level. Since the counterfactual real wage differential closely parallels the actual course of interregional wage differentials, I conclude that the smaller magnitude of twentieth-century wage differentials was due largely to a reduction in the magnitude of exogenous labor supply and demand shocks and not to changes in the extent of labor market integration.

It is tempting to conclude that the magnitude of real wage differentials in the late nineteenth century was due entirely to the forces which produced geographic imbalances in the supply and demand of labor, but this would ignore the fact that the effects of these forces were localized because labor markets were not completely integrated. There is thus no simple answer to the question of how well late nineteenth-century labor markets worked. They worked to the extent that labor supply moved from low- to high-wage areas, and labor market institutions responded to opportunities for arbitrage. But this responsiveness was not sufficient to eliminate or even reduce interregional real wage differentials over the course of nearly thirty years.

Joshua L. Rosenbloom, University of Kansas 